\title{
LA «CURA» DE HEIDEGGER COMO UNA CLAVE PARA EL DEBATE ECOLÓGICO ${ }^{1}$
}

\author{
JOSÉ LUIS CABALLERO BONO \\ Universidad Pontificia de Salamanca
}

\begin{abstract}
RESUMEN: Este artículo estudia la utilidad del concepto heideggeriano de «Sorge» para una filosofía de la ecología. Primero analiza las traducciones de la «Sorge» en lengua española. Un análisis crítico selecciona el concepto de «cura». En segundo lugar expone el significado de la "cura» en Heidegger. En tercer lugar muestra las posibilidades del concepto de «cura» para la reflexión ecológica: se hace aquí una interpretación de la obra de Hans Jonas, El principio de responsabilidad, como una derivación ecológica de la «cura» heideggeriana. De esta manera se afirma el «Dasein» como lugar de vinculación entre el hombre y la naturaleza.
\end{abstract}

PALABRAS CLAVE: Heidegger; «Sorge»; «cura»; filosofía de la ecología; apercibimiento.

\section{The Relevance of Heideggerian's Concept of "cura" in the Ecological Debate}

ABSTRACT: This article studies the use of Heideggerian concept of «Sorge» for a philosophy of ecology. First, analyze the translations of «Sorge» in Spanish language. A critical analysis chooses the concept of "cura». Second, present the meaning of "cura» in Heidegger. Third, show the possibilities of the concept «cura" for an ecological reflection: an interpretation of the work of Hans Jonas, The Imperative of Responsibility, is made here as an ecological derivation of the Heideggerian «cura». In this way, "Dasein» is affirmed as a place of connection between man and nature.

KEY WORDS: Heidegger; «Sorge»; «cura»; Philosophy of Ecology; Aperception-Warning.

En la historia de la divulgación de la obra Ser y tiempo, de Martin Heidegger, no ha pasado desapercibido el concepto de Sorge. A veces se lo ha traducido popularmente por "preocupación», conforme al sentido inmediato que recoge el diccionario. Sin embargo, el contenido semántico que Heidegger le atribuye a dicho concepto desautoriza esa traducción. Es cosa que se colige de cualquier exploración terminológica elemental. La preocupación por la salud de nuestro planeta no legitima, por sí misma, la comprensión inmediata de la Sorge como preocupación. No obstante, si es verdad que la vida es el tema del Heidegger temprano, y que la vida es una relación del hombre consigo mismo como la que se da en el «mundo de la vida $»^{2}$, entonces parece abrirse aquí un camino para acoger el concepto heideggeriano de Sorge en el marco de lo que hoy se denomina transición ecológica. Aunque vida no sea un concepto biológico, el horizonte hermenéutico último del ser humano cuenta con la vivencia de la naturaleza y de su exuberancia como ingredientes del mundo de la vida. Nuestro medio natural se acusa en los modos reflejos en que sale al paso la Sorge irrefleja y constitutiva de cada ser humano.

1 Este artículo se enmarca en el Proyecto de investigación: «La condición humana ante los retos de la Ecología» de la Cátedra Francisco José Ayala de Ciencia, Tecnología y Religión de la Universidad Pontificia Comillas (2016-2019).

2 Cf. Trawny, P., Martin Heidegger. Una introducción crítica, Herder, Barcelona 2017, pp. 23-24. 


\section{EXPloración terminológica: la traducción de SORGE}

En la primera versión de Sein und Zeit que se hizo al español, presentada como El ser y el tiempo en 1951, José Gaos tradujo el concepto de Sorge como "cura». Sin duda se veía respaldado por el texto en latín de Julio Cayo Higinio que Heidegger reproduce en el parágrafo cuadragésimo segundo de libro. Se trata de una fábula donde el concepto latino de cura queda personificado. Pero también pudo haberse apoyado en una tradición asociada a la Facultad de Filosofía de la Universidad Central de Madrid. Julián Marías, en efecto, en su Historia de la Filosofía de 1941 se sirve de esta palabra para referirse a la Sorge de Heidegger ${ }^{3}$. Lo que sugiere que pudo habérselo oído a su maestro, José Ortega y Gasset, o a algún otro profesor de la Facultad. Pues la obra como tal está confeccionada desde los apuntes de clase que tomó durante la carrera.

Cura significa varias cosas en latín, entre ellas tratamiento médico y obra literaria. Pero sobre todo acoge los dos significados principales que tiene el término Sorge desde el alto alemán antiguo, el de preocupación y el de cuidado, atención o solicitud. En latín es prioritario este segundo significado de cuidado - al contrario que en alemán-y así se ha mantenido en el vocablo italiano cura, que quiere decir cuidado y deja caer la acepción de preocupación. La encíclica del papa Francisco Laudato si' lleva por subtítulo Sulla cura della casa comune. Los traductores no han tenido duda: cuidado en español, Sorge en alemán, care en inglés. Curiosamente estas tres versiones encierran o pueden encerrar el matiz de inquietud y preocupación. Es decir, van más allá del sentido del término italiano. Sobre todo en la elección germana de un vocablo que evoca, prima facie, preocupación ${ }^{4}$.

Para un español corriente la palabra «cura» no hace pensar a bote pronto en preocupación ni en cuidado. Normalmente se asocia al ámbito de la sanidad (cura como sanación) o al ámbito religioso (cura como sacerdote) o al de los ultramarinos (cura de un queso, cura de un jamón). En los tres casos se puede hacer arqueología de las palabras y encontrar un efectivo significado de un proceso de cuidado y atención. Una cura de aguas no es un apósito que viene a cerrar de una sola vez una herida en un dispensario médico o en mi propia casa. La cura de almas —expresión que se ha mantenido en el diccionariono se identifica con un acto puntual, sino con un ministerio confiado para un periodo de tiempo: de ahí el sustantivo "cura» como nombre para el párroco, o para el eclesiástico en general, como quien desempeña dicho ministerio. La cura de un alimento, en fin, requiere tiempo y la preservación de ciertas condiciones ambientales.

\footnotetext{
3 Cf. Marías, J., Historia de la Filosofía, Editorial Revista de Occidente, Madrid 1947, p. 401.

4 La traducción alemana del subtítulo experimenta también una notable desviación de significado: Die Sorge um die globalen Gemeinschaftsgüter (La preocupación por los bienes globales comunes). Se ha perdido el concepto de casa que estaba en el original y que es etimológicamente justificador de la noción de ecología.
} 
En ninguno de los tres supuestos —el sanitario, el religioso y el alimentarioestá presente la idea de preocupación. El lector español de Heidegger se habituó desde los años cincuenta a la traducción de Gaos que soslayaba la dimensión de preocupación: Sorge es cura, y la cura puede sugerir el cuidado.

Pero el libro de Heidegger ha conocido una segunda traducción de la mano de Jorge Eduardo Rivera, culminada en 1995 y esta vez presentada con un título más acorde al original: Ser y tiempo. Y Rivera opta allí por traducir Sorge como cuidado. La razón inmediata de esta elección nos parece ser de índole cultural. Jorge Eduardo Rivera es chileno y conoce bien la traducción de José Gaos. Pero en Chile, cura significa borrachera. El distinto uso del idioma español podría conducir al equívoco de pensar que Heidegger está refiriéndose a una suerte de embriaguez, a una intoxicación etílica que de ninguna manera expresa fehacientemente el significado de Sorge. Por eso, una versión de la obra para el público chileno exigía una intervención quirúrgica sobre el texto de Gaos también en este punto. Un chileno hablaría de secado o maduración del jamón, no de cura del jamón; de queso maduro y no de queso curado o semicurado; de sanar en vez de curar.

La palabra «cuidado» tiene la ventaja de que aloja no solo el sentido de atención y solicitud por algo o alguien, sino también un secundario matiz de preocupación como ocurre con el término latino cura. Este matiz se advierte en giros negativos como "me trae sin cuidado», que quiere decir que no me preocupa, no me produce cuita alguna. Sin duda que la palabra cuidado es mucho más fácil de procesar para el lector ordinario de español que el vocablo elegido por Gaos. Mas no está exento de inconvenientes, como se mostrará.

Pero antes y después de José Gaos y de Jorge Eduardo Rivera se han ofrecido alternativas para la acomodación idiomática de la Sorge de Heidegger al español. Nos vamos a centrar en dos.

En 1932, un joven Xavier Zubiri, recién regresado de Alemania donde había sido oyente de Heidegger, durante un curso impartido en la Universidad Central se refiere a la Sorge como «solicitud $»^{5}$. En la década siguiente, su antiguo alumno Leopoldo Eulogio Palacios usa también «solicitud», pero con un manifiesto rasgo de preocupación y de diligencia ${ }^{6}$. Estos dos ejemplos llevan a pensar que «solicitud» pudo haber corrido como elección terminológica, a veces combinada con la de "cuidado», en un sector de la llamada Escuela de Madrid. Sería un modo de identificar la Sorge de Sein und Zeit antes de que Gaos hiciera canónica la traducción como «cura».

La palabra «solicitud» tiene el sentido de preocupación en latín (sollicitudo), como lo refleja el título de la encíclica Sollicitudo rei socialis (La preocupación

5 Cf. Zubiri, X., Cursos Universitarios. Vol. II, Alianza Editorial / Sociedad de Estudios y Publicaciones, Madrid 2010, p. 163. El curso se titulaba «Introducción a la filosofía desde la perspectiva del horizonte de la Creación».

6 Cf. Palacios, L.E., La prudencia política, Instituto de Estudios Políticos, Madrid 1946, p. 129. Dice de la solicitud que «un germano ha hecho consistir en ella nada menos que la estructura fundamental de nuestra existencia». 
por la cuestión social). Pero lo pierde en español, donde queda como «diligencia o instancia cuidadosa», según el Diccionario de la Real Academia Española de la Lengua. El mismo sustantivo «solícito» significa diligente, cuidadoso. Es decir, «solicitud» discurre semánticamente en la línea del cuidado y no de la preocupación.

Además, «solicitud» muestra un ribete temporal que está ausente en la idea de cuidado. Cuando se solicita algo se lo espera en un futuro, esto es, se pone uno en tensión de futuro, en protensión (como diría Edmund Husserl). El mismo nombre «solicitud» tiene también el sentido de un memorial en que se pide algo y, por tanto, se lo espera. Este matiz temporal es muy importante, porque la Sorge tiene en Heidegger una estructura temporal. Y precisamente el tiempo transcurre desde el futuro hacia el pasado.

Por último, y casi parece que a despecho de las opciones terminológicas que hemos recorrido, Juan Carlos Rodríguez ha propuesto en 2011 una traducción diferente, la de obsequio ${ }^{7}$. A primera vista puede resultar desconcertante, pues no parece guardar relación alguna con "preocupación», "cura» o «cuidado». Sería interesante saber de parte del autor si lleva implícita una crítica a esas opciones. En todo caso, dado que la Sorge de Heidegger no es un regalo o presente en sentido coloquial, "obsequio" puede tener que ver con el ocuparse de algo, que es sentido fundamental del «curarse de» ello. Este «ocuparse de», fundado en la Sorge, envuelve el dedicarse a ello y también el que ello esté dado, donado. Y esto sí parece recogido, como veremos, en el concepto heideggeriano de Sorge. Es, podríamos decir, un obsequio en ambas direcciones: obsequiarse al mundo en que se está y ser obsequiado con el mundo que está en nosotros, por más que ambas direcciones sean por lo regular atemáticas. La sugerencia de Juan Carlos Rodríguez nos parece importante y original, aunque llamada al equívoco como otras de las señaladas en este apartado.

\section{SENTIDO DE LA «CURA» COMO SER DEL «SER AHÍ»}

Heidegger desarrolla el estudio de la «cura» en Ser y tiempo, una obra que se propone despejar el horizonte para discernir el sentido del ser en general. Este trabajo previo se lleva a cabo mediante una analítica existenciaria del «ser ahí». Con esta última expresión, «ser ahí», designa el autor al ser humano en su existencia fáctica, concreta ${ }^{8}$. Y el adjetivo «existenciario» (existenzial) se refiere

7 Cf. Rodríguez, J. C., Para una lectura de Heidegger. Algunas claves de la escritura actual, Editorial de la Universidad de Granada, Granada 2011, p. 77. El autor combina esa traducción con la convencional de «cuidado».

8 No es este el lugar para desarrollar por extenso una justificación de por qué preferimos esta traducción, "ser ahí», a la alternativa de dejar tal cual la palabra alemana Dasein. Esta última palabra tiene uso en el alemán vulgar como existencia y existir. Pero el Dasein de Heidegger no significa existencia, para lo cual ya se sirve el filósofo de una palabra específica (Existenz). 
a un análisis ontológico, a diferencia de uno meramente óntico o existencial (existentiell) ${ }^{9}$. La diferencia entre lo óntico y lo ontológico - diferencia ontológica- es clave para un autor que denuncia la reiterada incomprensión del ser por haber sido confundido con un ente.

El análisis ontológico comienza identificando una estructura existenciaria del «ser ahí » que es el «ser en». El «ser en» se modula en esa totalidad de referencia que el autor llama mundo. El «ser ahí» es entonces un «ser en el mundo», es mundano y no solo intramundano como los entes. Consecuentemente, el «ser ahí» se comprende como un estar cabe algo, un estar familiarizado con, un habitar en. Notemos que el «cabe» es el «bei» alemán o el «chez» francés, la preposición que se emplea para decir que una persona está en casa, en su casa. El habitar evoca asimismo la idea de morada o casa. El «ser en» conviene entonces muy bien, de manera preparatoria, con la idea de que el medio ecológico es nuestro oĩ́ós (oikós), es nuestra casa. La poseemos y nos posee (nos cuesta cambiar de casa, cosa en este caso inviable por el momento). La convivencia con el medio ecológico sería una manifestación del «ser en el mundo» ${ }^{10}$. El cual, se nos advierte, no es una mera inclusión espacial, sino que el mundo es también un ingrediente del "ser ahí». Es una suerte de inmanencia recíproca, por así decir. Esto se traduciría en el plano de lo óntico en que la naturaleza está en el espíritu y el espíritu está en la naturaleza.

Sobre la base del «ser en» se descubren tres estructuras existenciarias que el filósofo de Meßkirch presenta y despliega ante el lector: el encontrarse, el comprender y el habla. Las tres son igualmente originarias. Pero las tres, y el «ser en» mismo, son posibles por algo más fundamental: la «cura».

¿Qué es entonces la «cura»? En sentido estricto no es cuidado o preocupación, cuita, solicitud. Esto serían manifestaciones posibles de la «cura». Lo que sea la «cura» se entiende desde lo que es el «ser ahí». Y el «ser ahí» es para Heidegger el lugar donde se manifiesta privilegiadamente el ser y puede plantearse la pregunta por el ser. En este sentido, Ramón Rodríguez ha escrito atinadamente que el «ser ahí» es el «ahí del ser»"${ }^{11}$. No se trata de un lugar espacial. El «ser ahí» dice Heidegger que es aquel ser al que le va su propio ser $(\S 4)^{12}$ o el ente a cuyo ser le es inherente la comprensión del ser (§ 39). Y si la pregunta filosófica es la pregunta por el ser, el «ser ahí» es el lugar donde surge y retorna esa pregunta

9 «Existenciario» corresponde al alemán existenzial, mientras que «existencial» corresponde a existentiell. La traducción ha oscilado. Mientras que Jorge Eduardo Rivera llama a lo existenzial existencial y a lo existentiell «existentivo», Enzo Paci utilizó en cambio «existentivo» para referirse lo existenzial. Aquí nos ceñimos a la versión de Gaos: existenciario está en la línea de lo ontológico, existencial de lo óntico.

10 Aunque el «ser en el mundo» sea ontológico, «Ser es en todo caso el ser de un ente»: Heidegger, M., El ser y el tiempo, sexta reimpresión, Fondo de Cultura Económica, Madrid 1987 (1951), p. 18.

11 Rodríguez, R., Heidegger y la crisis de la época moderna, Editorial Cincel, Madrid 1987, p. 69.

12 Los parágrafos entre paréntesis señalan el lugar de Ser y tiempo al que acudir para confrontar. Prescindimos de las siglas para esta remisión. 
(§ 7). Ahora bien, esta circularidad entre ser y «ser ahí» queda expresada en el concepto de apertura (Erschlossenheit).

Heidegger escribe que el «ahí» del «ser ahí» mienta el esencial estado de abierto de este ser peculiar, y para caracterizar la disolución de su ser más propio en la mediocridad cotidiana dice metafóricamente que «echa el cerrojo» a su propio ser (§ 28). Friedrich-Wilhelm von Herrmann ha destacado la Erschlossenheit o apertura como la nota distintiva del «ser ahí»" ${ }^{13}$. La comunicación «con» y «del» ser que se opera en el «ser ahí» nos parece que puede contemplarse como una buena base para pensar la relación del hombre con el medio ecológico, sin detenernos en la desaparición del sujeto que denuncia Von Herrmann y que se ha convertido en una tesis ya clásica en la interpretación de Heidegger.

Pues bien, a la hora de caracterizar la «cura» es fundamental darse cuenta de que es una forma de estar el «ser ahí» abierto a sí mismo. Quizá deberíamos decir que es la forma por excelencia de apertura a sí mismo, es la base de cualquier «en consideración de sí mismo» que pueda verificarse en el existir de aquel ser al que le va su propio ser.

Por cuanto llevamos dicho puede comprenderse que optemos sin complejos por la traducción de Sorge por «cura», con la que se presentó la primera traducción de Sein und Zeit a nuestro idioma. Y ello a pesar de que algunos especialistas en Heidegger de lengua española han seguido prefiriendo el término «cuidado» ${ }^{14}$. Las comillas de «cura» son una alerta que disuade de una interpretación ordinaria. Y la pátina de arcaísmo que presenta se justifica por el origen latino explícitamente aducido por Heidegger.

El hilo conductor para detectar el sentido exacto de la «cura» y evitar precisamente malentendidos por el uso cotidiano del lenguaje lo proporciona Heidegger por el análisis de un modo peculiar del encontrarse, la primera de las tres estructuras existenciarias - encontrarse, comprender, habla- ahormadas en el «ser en el mundo». Ese modo es el temple o afección de ánimo que llama angustia.

La angustia no es primariamente un miedo sin objeto, sino en todo caso un miedo del «ser ahí» ante sí mismo. No ante un objeto intramundano, sino ante su propia mundanidad enrarecida. Ocurre, en efecto, que el «ser ahí» vive por lo regular en una forma degenerada de su ser más peculiar, forma que recibe el nombre de caída. La angustia es un salir del estar engolfado en la caída -un desviarse de ella, como el clinamen de Epicuro- para "caer» en la cuenta el «ser ahí» de que está cayendo, de que no está en su casa. De ahí el carácter de

13 Cf. Von Herrmann, Fr.-W., Subjekt und Dasein. Interpretationen zu «Sein und Zeit», Vittorio Klostermann, Frankfurt a.M. 1985, p. 21.

14 Cf. Adrián Escudero, J., El lenguaje de Heidegger. Diccionario filosófico 1912-1927, Herder, Barcelona 2009, p. 156ss. Asimismo el libro de Ramón Rodríguez citado. También en inglés se ha mantenido la tradicional traducción de Sorge por care. Cf. Mulhall, S., The Routledge Guidebook to Heidegger's Being and Time, Routledge, New York 2013, pp. 112-114, 132 , 140, 142, 156, etc. En cambio, Arturo Leyte no ha tenido inconveniente en conservar la inveterada traducción «cura». Cf. LeYTE, A., Heidegger, Alianza Editorial, Madrid 2005, p. 125. 
inhospitalidad que acompaña a la angustia. Pero también la posibilidad que ofrece de una vuelta del «ser ahí» sobre sí mismo.

Ahora bien, esta vuelta sobre sí mismo es capital. El parágrafo 41 de Ser y tiempo nos dice en su título que la «cura» es el ser del «ser ahí». Y comienza la explicación de la «cura» con la autorreferencialidad: el «ser ahí» es un ente al que en su ser le va este mismo. Este ser más allá de sí mismo como ser relativamente al poder ser que es él mismo es una intencionalidad de futuro que Heidegger llama pre-serse. Esto es, ser por anticipado. Creemos que ello conecta muy bien con la caracterización que hizo Julián Marías del hombre como ser "futurizo", enderezado al futuro, como característica de su ser persona. Incluso etimológicamente designa «persona» una careta para la parte frontal de la cabeza, la que mira hacia adelante ${ }^{15}$. El pre-serse conecta también con el sentido heideggeriano de la existencia como automodulación del «ser ahí» de su propio ser. Ser de cara a su ser modulándolo es la existencia (§ 9).

Pre-serse es algo ya fáctico, se da en el «ser en el mundo» - no en el animal ni en la piedra- y en él está encerrada la caída en el «ser cabe».

Entonces, el ser del «ser ahí» o «cura» es un anticiparse a sí mismo en el mundo como un estar en medio de los entes que comparecen en el mundo. $\mathrm{O}$, dicho literalmente, «cura» es:

«pre-ser-se-ya-en (el mundo) como ser-cabe (los entes que hacen frente dentro del mundo) $»^{16}$.

Esta fórmula de apariencia enigmática decimos que expresa el ser del «ser ahí». La «cura» es un anticiparse dentro del tener que ver ya con todo que es el "ser en el mundo». Merece la pena recordar esto, aunque ya sea perceptible en una primera lectura pausada de Sein und Zeit ${ }^{17}$.

Varias veces dice Heidegger que la esencia del «ser ahí» es la existencia. Pero cuando habla del ser (Sein) del «ser ahí» se refiere a la «cura». Así lo atestigua ya el título del capítulo sexto de la obra.

La secuencia "pre-serse, en el ser-ya-en, como ser-cabe» tiene una estructura eminentemente temporal, donde se suceden intencionalidad de futuro o pro-tensión (pre-ser-se), intencionalidad de pasado o retención (ser-ya) e intencionalidad de presente (ser-cabe), todo dentro de un marco claramente autorreferencial. Esto se compadece con la afirmación traída en los comienzos de Ser y tiempo de que el sentido del ser del «ser ahí» es la temporalidad. Y consecuentemente nos avisa que la «cura» tiene una relevancia para el sentido del ser en general, cuya exégesis es el objetivo de la obra. Como mínimo nos

15 Cf. Marías, J., Antropología metafísica, Editorial Revista de Occidente, Madrid 1973, p. 22 y, especialmente, p. 42.

16 Heidegger, M., op.cit., p. 213.

17 Por otra parte, tampoco está de más repasar contenidos elementales. La traducción de Sein und Zeit al francés, por ejemplo, es tan reciente (1986) que es fácil que siga habiendo interpretaciones divulgativas inexactas. 
pone sobre aviso de si el ser no tendrá una estructura circular como la «cura» o la comprensión.

Pero la estructura temporal de la «cura» también se compadece con el hacer el hombre su vida - la vida no se nos da hecha, decía Ortega y Gassetporque, en un tiempo que discurre del futuro al pasado, anticipa su más propia posibilidad $^{18}$.

\section{PARA UNA LECTURA ECOLÓGICA DE LA «CURA»: «CURA» COMO APERCIBIMIENTO}

La partícula «sorg», que figura como prefijo de Sorge, permite una serie de construcciones en lengua alemana: das Besorgen, die Fürsorge, die Sorgfalt ... Con esta partícula juega Heidegger para dar cuerpo a los diversos conceptos. Das Besorgen es el ocuparse de algo o "curarse de» ello; die Fürsorge es la atención a otro asistiéndole; die Sorgfalt es el cuidado, con el matiz de lo concienzudo (etimológicamente incluye el concepto de Falten, las arrugas que se forman en la frente cuando se hace algo con prurito de exactitud). Tanto Fürsorge como Sorgfalt expresan el cuidado mejor que Sorge.

La «cura» (Sorge) colorea el "ser en", y por eso los distintos modos de «ser en» tienen la forma del «curarse de». Estos modos son muy variados: tener que ver con algo, producir algo, encargarse y cuidar de algo, emplear algo, abandonar y dejar que se pierda algo, emprender, imponer, examinar, indagar, considerar, exponer, definir, dejar, renunciar, descansar, etc. (§ 12). El «curarse de» parece entonces designar toda forma de habérselas con algo. Incluidos el temor y la precaución, como cuando decimos «curarse en salud». Cuando ese habérselas es con otros que tienen la misma forma de ser del «ser ahí», entonces hablamos de Fürsorge. Es la atención al otro que conlleva asistirlo, ayudarlo o cuidar de él. Gaos lo traduce como «procurar por», lo cual más parece velar su sentido que transparentarlo.

Ahora bien, si el «curarse de» es tan originalmente cuidado como descuido o incuria, difícilmente podremos aceptar que la «cura» sea formalmente cuidado o preocupación. Es pre-ocupación si tomamos esta expresión compuesta en sentido literal, dado que está antes del "curarse de», que es siempre un ocuparse de algo. Pero en sí misma no comporta necesariamente inquietud o solicitud. La estructura autorreflexiva de la "cura» se complementa con la inclusión del mundo de que se cura, no es egocentrismo. Por eso, en la apertura del «ser ahí» a sí mismo está abierto también al mundo, pero más aún: el mundo está abierto a él. Esta apertura del mundo al hombre, que conlleva un poder

18 En el semestre de invierno de 1921, Heidegger analiza la experiencia de la temporalidad en la existencia cristiana primitiva y encuentra decisivo el ponerse en situación de alerta (Not) de cara a la plenitud futura que representa la parusía (cf. Heidegger, M., Phänomenologie des religiösen Lebens. I. Einleitung in die Phänomenologie der Religion. 2. Augustinus und der Neuplatonismus. 3. Die philosophischen Grundlagen der mittelalterlichen Mystik, Vittorio Klostermann, Frankfurt a.M. 1995, p. 98). 
modulador del primero sobre el segundo, queda reflejada en la fábula 220 de Cayo Julio Higinio que cita Heidegger. En ella, Cura, como forma personalizada y externa al hombre, da forma al ser del hombre. Cura es aquí un ente (por tanto, intramundano), por lo que Heidegger se sirve de la fábula como una ilustración pre-ontológica de lo que quiere decir. Por su belleza y por su riqueza de evocación ecológica, reproducimos el pasaje en la traducción que hizo José Gaos de la propia versión de Heidegger:

«Una vez llegó Cura a un río y vio terrones de arcilla. Cavilando, cogió un trozo y empezó a modelarlo. Mientras piensa para sí qué había hecho, se acerca Júpiter. Cura le pide que infunda espíritu al modelado trozo de arcilla. Júpiter se lo concede con gusto. Pero al querer Cura poner su nombre a su obra, Júpiter se lo prohibió, diciendo que debía dársele el suyo. Mientras Cura y Júpiter litigaban sobre el nombre, se levantó la Tierra (Tellus) y pidió que se le pusiera a la obra su nombre, puesto que ella era quien había dado para la misma un trozo de su cuerpo. Los litigantes escogieron por juez a Saturno. Y Saturno les dio la siguiente sentencia evidentemente justa: "Tú, Júpiter, por haber puesto el espíritu, lo recibirás a su muerte; tú, Tierra, por haber ofrecido el cuerpo, recibirás el cuerpo. Pero por haber sido Cura quien primero dio forma a este ser, que mientras viva lo posea Cura. Y en cuanto al litigio sobre el nombre, que se llame 'homo', puesto que está hecho de 'humus' (tierra)"»"19.

Este texto es un testimonio del carácter de fundamento de la "cura». Subraya, eso sí, la apertura del universo (aquí un universo mitológico) al hombre. Pero es que esa apertura va ínsita en el abrirse el «ser ahí» a sí mismo por ser un ser que incluye al mundo.

La circularidad entre hombre y mundo en tesitura de anticipación es lo que nos parece que define más propiamente el fenómeno de la «cura». Este mutuo «darse» el uno para el otro es lo que dota de pertinencia a una concepción de la «cura» como obsequio, según la propuesta de Juan Carlos Rodríguez que hemos registrado en el primer apartado de este artículo. Pero como la entrega es un fenómeno fundado parece recomendable explorar un concepto más originario para la «cura», y este es el que creemos ver en la noción de apercibimiento.

Habría que entender el apercibimiento no en sentido gnoseológico, sino en sentido ontológico, algo así como la apercepción que asigna Leibniz a las mónadas espirituales. Apercibimiento tiene un evidente matiz reflexivo como reditio in seipsum, vuelta sobre sí. Pero en su uso normal recoge también un significado de admonición o amonestación disciplinaria que nos viene de fuera. Quitando el carácter de corrección nos interesa, eso sí, la procedencia del exterior. Es esa procedencia la que puede fundar una cualificación de la vivencia del mundo y aun de uno mismo en el plano óntico. Pero en un nivel ontológico podría quedar formalmente caracterizada la «cura» como puro apercibimiento que unifica a hombre y mundo en el «ser ahí».

El vínculo del apercibimiento es el que justifica el que Heidegger, no obstante, reconozca ulteriormente que «de manera privativa o negativa» la «cura» siempre

19 Heidegger, M., El ser y el tiempo, op. cit., pp. 218-219. 
es ya un «curarse de» $\mathrm{u}$ «ocuparse de» $\mathrm{y}$ —atención al segundo miembro de la conjunción - un atender o «procurar por» (§ 41). Este segundo miembro es el que expresa explícitamente el contenido del cuidado y la preocupación.

Pero, ¿qué quiere decir «de manera privativa o negativa»? Quiere decir: prescindiendo del nivel ontológico. Es decir, de manera óntica es siempre la «cura» una asistencia al otro y eso conlleva un cuidado del mundo, pues el otro es «ser en el mundo» ${ }^{20}$. Entonces, por decirlo escolásticamente, aunque la Sorge no sea in modo recto cuidado o preocupación, sí que lo es in modo obliquo.

Al leer las consideraciones de Heidegger puede plantearse legítimamente la pregunta: ¿a qué se parece más la «cura» heideggeriana, a la cura de almas o a la cura del jamón? La cura de almas sería la atención al otro y el subvenir a sus necesidades, y la cura del jamón el respeto a los ritmos de la naturaleza.

Ahora estamos en condiciones de decir que no es posible una disyuntiva o exclusión entre ambas. El cuidado del «ser ahí» propio y ajeno conlleva el cuidado del mundo. Y la conservación de la naturaleza obliga a preocuparse por el hombre que forma parte de ella. En el supuesto de que Heidegger fuera ecologista, no sería un activista a ultranza que defendiera un ecologismo desvinculado de la suerte del «ser ahí». El respeto a la naturaleza (la cura del jamón) puede revestir tintes de «dejamiento»(Gelassenheit), pero no de papar moscas (gaffen) en detrimento del ser humano. El mismo poder oscuro del verbo de Heidegger asigna a la mundanidad una doble pertenencia, pues es del mundo y es del «ser ahí» (§ 18). Una vinculación entre hombre y naturaleza que transparece en el concepto mismo de oĩ́ós (oikós) que está a la base del prefijo «eco-». El término griego no designa ni pura naturaleza virgen, ni, por un imposible, habitación completamente artificial, sino un término medio entre ambas. A diferencia de oıkía (oikía), que es la casa como apartamento (y apartamiento de la naturaleza), oĩkós es la casa que incluye el huerto y los animales domésticos, además de los esclavos cualquiera que sea su valoración. Es una naturaleza labrada por el hombre, pero que permite todavía atisbos de la naturaleza en su faceta no humanizada.

La virtualidad de la «cura» para un planteamiento filosófico del problema de la ecología se echa de ver en la obra emblemática de un discípulo de Heidegger. Nos referimos a El principio de responsabilidad, de Hans Jonas. La conexión de esta obra con la «cura» heideggeriana podemos verla en varios detalles.

En primer lugar, el carácter proléptico de la «cura», su calidad prospectiva, coincide con la advertencia de Jonas según la cual la responsabilidad por la humanidad futura, por el planeta futuro, es una responsabilidad por lo que no existe, hacia lo que no existe: precisamente el futuro ${ }^{21}$. Solo en las dimensiones de ese futuro parecen no coincidir Heidegger y Jonas. Mientras que Jonas piensa en un futuro que puede ser bastante lejano y de toda la humanidad,

20 Hablando de los sentidos de la «cura» en la carta 124 de Séneca a Lucilio, solicitud y entrega, Heidegger dice que son sentidos ónticos. Cf. Ibíd., p. 218.

${ }_{21}$ Cf. Jonas, H., El principio de responsabilidad. Ensayo de una ética para la civilización tecnológica, Herder, Barcelona 1995, pp. 160, 164, etc. 
Heidegger piensa en términos de la duración de una vida humana, puesto que la «cura» es del «ser ahí» individual. Por esta brevedad se ajusta más a los tiempos que maneja el actual concepto de sostenibilidad, que prevé resultados de acción en un arco de un máximo de unos cien años.

Pero, en segundo lugar, el primer mandamiento que formula Jonas para su ética es la existencia de la humanidad futura ${ }^{22}$. Es por mor de esa humanidad por lo que merece la pena conservar el planeta, y en esto coincide con el cuidado o atención ónticos por los demás como vía heideggeriana de descubrimiento del cuidado que merece la naturaleza.

Mas, en tercer lugar, el carácter mismo del apercibimiento está contenido en el concepto de responsabilidad. Pues este no recoge más que el carácter responsivo o respondente del hombre frente a algo que le percute o llama desde fuera de él ${ }^{23}$. La estructura circular o autorreferencial está así asegurada en el concepto de responsabilidad, que es una re-percusión. Heidegger diría que la responsabilidad es hecha posible por la «cura», pues no es sino una forma de «curarse de».

Por último, el libro de Jonas lleva como subtítulo: Ensayo de una ética para la civilización tecnológica. Cuando lo leemos, sin embargo, no encontramos ningún tipo de instrucción sobre cómo actuar, qué medidas concretas adoptar ante el inmenso problema de las consecuencias que tiene el desarrollo tecnológico sobre la salud del planeta. No sabemos cómo «curarlo». Y es que probablemente Jonas solo ha pretendido fomentar una mos, un acostumbramiento interior a la receptividad para ese problema, sin determinar vías concretas de solución. Ha tratado, como diríamos en mal castellano, de concienciarnos. Ahora bien, esto es justamente lo que, en esquema, ofrece la verdad de la vinculación entre hombre y mundo que se verifica en el «ser ahí».

En otras palabras, y sin afirmar que lo haya pretendido, Hans Jonas ha ofrecido una deriva ecologista consecuente del concepto heideggeriano de «cura». Esto, por supuesto, sin obviar otras líneas de influencia como la kantiana, bastante reconocible. Y con ello ilustra este acceso una línea de interpretación posible de la «cura».

\section{CONCLUSIÓN}

Partiendo del concepto ontológico de Sorge, admitiendo su traducción posible como "cura», hemos analizado el contenido de este concepto para una reflexión filosófica sobre la ecología. Si bien en su estricto sentido no tiene la acepción de cuidado o de preocupación, su trasposición óntica sí la tiene.

El evidente sello temporal de la «cura» se relaciona con la posibilidad del «ser ahí» de abrirse a su plenitud futura modulando su vida. No otra cosa es la

22 Cf. Ibid., pp. 173ss.

$23 \quad$ Cf. Ibid., p. 153. 
existencia. Y de ahí que sea precipitada la contraposición que a veces se hace entre la «natalidad» de Hannah Arendt y el «ser-para-la-muerte» de Heidegger. $\mathrm{La}$ «natalidad» no es sino la espontaneidad de la libertad humana ${ }^{24}$, que de ningún modo nos está sustraída por el hecho de que no seamos actores de nuestro comienzo ni de nuestro final. Antes bien, esta espontaneidad dota de contenido efectivo al carácter anticipatorio de la «cura» y permite hacer el trasvase óntico a términos de cuidado y preocupación.

Se es ya siendo en el mundo. No hay ni puede haber indiferencia estricta entre espíritu y naturaleza. Dentro de nuestro espíritu la naturaleza se erige en una instancia para la responsabilidad. El paralelismo entre apercibimiento y responsabilidad ha permitido una clave de lectura de la ética de Hans Jonas desde la «cura» heideggeriana. Tal vez merece la pena añadir el detalle biográfico, poco conocido, de que Heidegger redactó Ser y tiempo mientras sus dos hijos eran pequeños. Por eso no lo escribió en su famosa "cabaña», sino en una casa al verdadero estilo campesino de la Selva Negra que estaba a unos sesenta metros más abajo ${ }^{25}$. Necesitaba retiro para escribir, pero en su concepto de «cura» parece reflejarse esa responsabilidad óntica que Hans Jonas presenta como paradigmática: la responsabilidad por la prole, que nos aparece de inmediato como origen de un deber nuestro sin concesiones hacia una realidad cargada de futuro.

Desde luego que la sensibilidad de Heidegger hacia el paraje natural de Todtnauberg no queda sepultada por el aparato conceptual, sino que emerge de manera expresa en el parágrafo 22 de Ser y tiempo. Allí dice que la casa tiene su fachada que da al mediodía y su fachada al norte, en relación a ellas está orientada la distribución de los espacios y dentro de ellos el arreglo de los enseres. Esto es exactamente lo que ocurre en la cabaña: la fachada sur es la de entrada; a ella dan el comedor, el cortavientos y el dormitorio. La fachada norte es la que cobija el tendedero y el excusado. En el centro están, separados, el hogar de la cocina y el despacho del filósofo. Hasta el día de hoy, ese santuario del pensar sigue descubriéndonos, a poco que nos curemos de él, la naturaleza. La densidad de una nevada se adivina con solo mirar el reclinado alero norte en un día de diciembre. El sonido de la fuente sigue oyéndose.

$\mathrm{El}$ «curarse de» los hijos y el «curarse de» la naturaleza se manifiestan como expresión de un mismo fenómeno que reúne herencia y tarea. La «cura» se revela como clave de una ecología integral por integradora del mundo y del hombre.

José Luis CaBallero Bono

[Artículo aprobado para publicación en enero de 2019]

24 Cf. Arendt, H., La condición humana, Paidós, Barcelona 2005, p. 207.

25 Cf. Sharr, A., La cabaña de Heidegger. Un espacio para pensar, Editorial Gustavo Gili, Barcelona 2008, p. 56. 